\title{
COMPACT BONE AS A NON-ISOTROPIC MATERIAL
}

\author{
WILFRID T. DEMPSTER AND RICHARD T. LIDDICOAT \\ Department of Anatomy and Department of Engineering Mechanics, \\ University of Michigan, Ann Arbor.
}

EIGHT FIGURES

INTRODUCTION

Bones, apart from their marrow functions and their functions as mineral depots, serve the body as rigid structural members. As such they protect the central nervous system and the eranial, thoracic and pelvic viscera; they support and give form to the body mass, and they serve as the essential levers in the rotational movements of the body segments. As mechanical structures, they lie within fields of force. They may react to given force vectors either actively through movement or passively, within the limits of their strength, by offering resistance.

A perfectly rigid body, however, is an abstraction, and various structural materials - such as cement, wood, or steel - differ greatly in properties such as strength, toughness, elasticity, brittleness and yielding or plastic properties. It is not yet feasible to define the properties of osseous material in all parameters in the way that many engineering materials are known. Until this knowledge is available, it will not be possible to make reasonably complete and discriminative correlations between bone morphology and bone properties.

Our task, here, is the examining of test samples of human bone to determine certain properties and how they vary in different axes. Compact bone will be shown to be non-isotropic - that is, it does not have the same physical properties in every direction. 
Literature. Previous studies on the physical properties of samples of compact bone have been limited to the large bones of the free extremities. Since all work has involved test samples from dead material under different conditions, all results must be viewed only as approximations of the properties of living bone. Wertheim (1847), as the first modern worker, measured the strength and elasticity of test specimens from several human bones. Rauber (1876), in an important definitive monograph, reported studies on the density, strength and elasticity, among other features, of fresh human and mammalian bone. Fresh, in this connotation, implies merely recent and unpreserved material, since the preparation and testing of samples from a bone require an appreciable time post-mortem. Hülsen (1898, abstract by Schaffer, 1898) dealt with the elasticity and strength of fresh animal bone including human. (Over a half-century span, little additional information accrued. Koch ('17) determined no properties other than specific gravity from test pieces of a human femur preparation. Hallermann ('35) measured properties of beef bone. Marique ('45) tested pieces of presumably dry skeleton femur for strength and elasticity.

More recently in this country, preserved tibial and femoral bone from the dissecting room was tested for specific gravity, tensile and compressive strength and modulus of elasticity by Carothers, Smith and Calabrisi ('49). In addition, Calabrisi and Smith ('51) showed that embalming ordinarily weakened the strength of bone, and that very small test specimens gave as valid strength data as larger specimens. Evans and Lebow (51) studied tensile and shear strength, tensile modulus of elasticity, Rockwell hardness, and percentage elongation under tension on test samples from preservedcadaver lower-extremity bones. The latter study has shown that certain properties of bone differ regionally in the femur and tibia. More recently, Evans and Lebow ('52) reported continuations of their studies on tensile testing of bone. Test specimens from femora, tibiae and fibulae were tested for tensile strength, percentage elongation and energy absorbing 
capacity. Both regional differences in these properties and differences between the types of bone were recognized. Neither tensile strength nor percentage elongation showed a consistent trend relative to age. Drying of test specimens reduced percentage elongation and energy absorption values but increased tensile strength.

Though Rauber's classical work and that of Inïlsen were for years the definitive studies on the properties of human bone, they are inadequate by present standards, and further researches are warranted. Rauber's strength tests and his elasticity modulus studies appear to have been derived from bones from test groups of only 4 or 5 individuals. His comparisons of wetted versus dried bone, or warmed versus cooled, were on very small samples. The same was true of his parallel-to-fiber and cross-fiber tests. ('The terms parallel to fiber and cross fiber are based on the predominantly longitudinal orientation of Haversian systems and fiber means much the same as "grain" in wood.) The older testing machines were cumbersome devices. Rauber's elasticity modulus values, for example, were derived from data on bending. Moreover, it has been largely since Rauber's day that the labile and plastic aspects of living bone have been recognized. Evidence (Murray, '36; Weinmann and Sicher, '47) is now at hand to show that over days, weeks or months, living bone may change its gross or microscopical morphology in response to growth, to dietary factors, to hormonal influences, to disease, to injury, to disuse, and to persistent forces. The extent to which physical properties may be correlated with such morphological changes is, however, speculative.

\section{MATERIAL}

Our data are from cleaned and dried adult macerated skeletal preparations of a number of femora (31) tibiae (10) and humeri (5) from the osteological collection at the University of Michigan. No data on age, sex, race or method of preparation were available on the selected bones. Medium 
to large size adult bones were taken at random except for avoidance of obvious pathology. Specimens of compacta for tension tests were of two types: lathe-cut spindles 5 to 6 inches long and approaching a quarter inch thickness were shaped with a two-inch middle span of reduced section having a 1.5 to 2 tenths inch diameter (fig. 1a); or rectangular prisms of similar length and thickness were machined with a correspondingly reduced middle section. The routine compression specimens (fig. 1b) were columns of rectangular or circular section having a length thickness ratio of $7 \pm: 1$. Specimens were cut from the middle thirds of the bones, ordinarily from the anterior face or sides where the thickest possible straight piece could be taken. Test pieces, sawed from the bones and machined to shape, were examined as they were - "dry" - or after soaking in water overnight to 24 hours - "wet." Test pieces from one middle-aged male, unpreserved but refrigerated for some days, constituted our only "fresh" specimens.

\section{Elastic properties}

Bone, like other solid structural materials, is not perfectly rigid; a bar of bone under tension is elongated and a bar in compression is shortened as loads are applied. The amount of change in length due to either lengthening or shortening under loading is known as strain, and it is measured as the ratio of the change to the original dimension in which the change occurred. The total deforming force divided by a cross-section area of the material is known as the stress at that section. A material is considered to be perfectly elastic and may be said to obey Hooke's law if a series of successive stresses of different value cause deforming strains which are proportional to the stresses.

This relationship for bone is illustrated in figure 1a. A test spindle of dry compact bone, machined with a reduced middle section, was gripped at each end in an engineering 


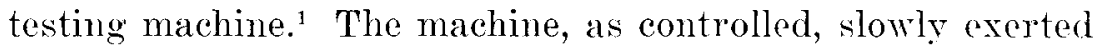
an end-to-end pull (tension) on the specimen, and the tensile force at any instant was registered on a dial gage. The total tension force at any moment divided by the minimum cross-sectional area of the reduced section represented the tensile stress active at this region of the spindle.

Tension values well below the breaking stress caused an elastic elongation or stretching of the bone, especially in the narrowed region. The amount of increase in length (tensile strain) was measured by a small gage ${ }^{2}$ which was fixed along a standard span or gage length of the reduced section. Two extensometers, one on each side of the reduced section, compensated for possible ecentricities in the loading of the test piece and thus gave more consistent records than one gage alone. Both one- and two-gage records have been made in tests referred to later.

Figure 1a (solid line) shows a plot of the tensile strain values for dry bone that parallel a series of selected values of tensile foree-plotted in terms of stress. The straight line region $(O$ to $A)$ indicates a proportionality of stress and strain in line with Hooke's law. The upvermost points beyond the proportional limit $(\mathrm{A})$ show a deviating curve ( $A$ to $\mathrm{X}$ ) before the breaking of the bone (at $\mathrm{X}$ ). This deviation from the curve of proportionality $\left(\mathrm{O}\right.$ to $\left.\mathrm{A}^{\prime}\right)$ indicates that the bone was stretched more proportionately by the higher stresses than by those in the lower elastic range. Moreover, such excessive stretching permanently altered or damaged the bone. This alteration of elastic stretching beginning at the proportional limit involved stresses about half the value of those which broke the bone.

${ }^{1}$ Various standard testing machines according to the problem at hand were used in the experiments: Baldwin-Southwark Universal, Amsler Universal, Sonntag Universal, Dillon Tensile Tester, and Olsen Universal. In general, a loadirg rate of approximately $200 \mathrm{lbs}$. per square inch per minute was used for the modulus tests in this study, and approximately $400 \mathrm{lbs}$. per minute for the strength tests.

2 Three types of extensometer, or strain gage, were used in experiments: PorterLipp, IJuggenberger, or Tuckermann. 
The dashed curve, representing wet bone, in tension shows an elastic range (O-A) like dry bone, but as the spindle elongated further toward its breaking point (X) the proportionality between stress and strain ended earlier though again at a proportional limit about half the breaking stress. Beyond this proportional limit, each later increment in stress caused excessive yielding and permanent plastic deformation.

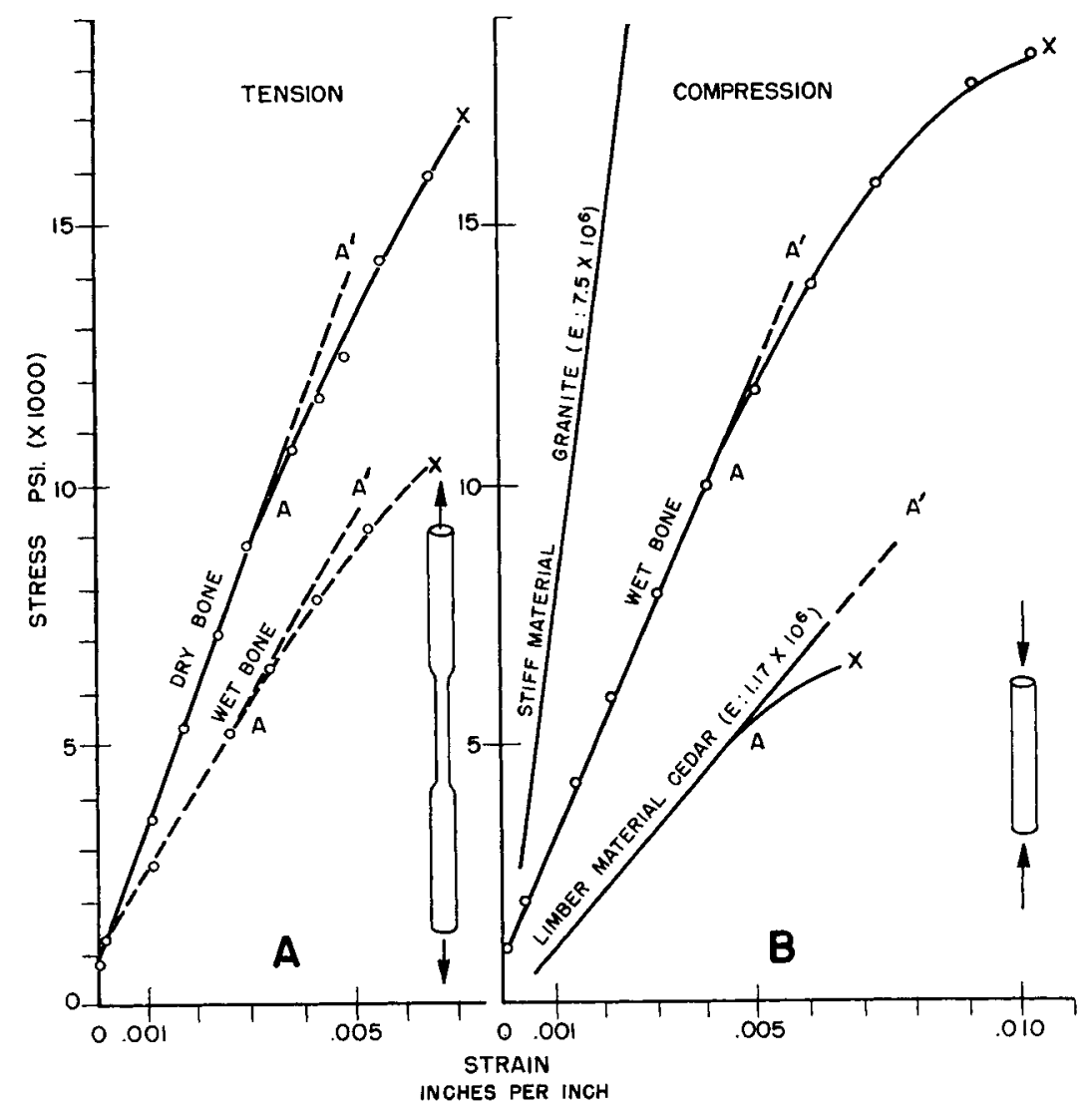

Fig. 1 A, Stress-strain curves for dry and for wet compact bone in tension. (A, proportional limit; $X$, breaking point; $O-A^{\prime}$, slope of perfectly elastic range, and $A-X$, range of plastic deformation.) The insert figure shows the shape of test spindles.

$\mathrm{B}$, Stress-strain curve for wet bone in compression. (Symbols $A, A^{\prime}$ and $X$ ats above.) The insert figure indicates the shape of test columns. Comparative curves for a stiffer and a more limber material are shown also. 
In both the straight part of the curve and in the deviating plastic region, greater strains were produced than in dry bone by a given stress.

The curve for wet bone in compression (fig. 1b) is again similar to those discussed. The curve shows an elastic range (to A), a proportional limit about half the breaking strength, and an inelastic range prior to failure. The stresses for a given strain for bone in compression were somewhat higher than those for wet bone in tension but they were about the same as those for dry bone in tension. If, in the situations illustrated, the tensile or compressive forces were released within the straight line portion of the curves, the bone resumed its normal length. Furthermore, repeated tests on a given specimen produced essentially duplicate curves - as long as stresses were not raised above the proportional limit.

If a stiffer material, such as granite, were similarly tested in compression and brought through the same stress range, it would show less strain for corresponding stresses (fig. 1b). The straight line of the steeper curve (for granite) again implies that the strain was proportional to the stress. A more limber material (cedar wood) also showed the characteristic proportionality over the first part of its compressive stress-strain curve. The slope of the straight-line portion of the curve, however, was lower. In order to eompare - in either tension or compression -- the elasticity of one material that obeys Hooke's law with another, i.e., to compare the straight line parts of the curves, a factor that implies the stiffness of the material is convenient. The standard measure of this factor, known as the elasticity modulus (Young's modulus), has been conventionally expressed as the amount of stress (force per unit area) theoretically required to produce a unit strain in the material through purely elastic deformation. This notation, of course, is only a mathematically extrapolated relationship. For instance, if a material of given stiffness on testing within its elastic range yields .001 in. per inch of original length when stressed by 2000 psi (pounds per square inch cross section), the ratio of these values may 
be expressed arbitrarily as 2,000,000 psi (or $2.0 \times 10^{6} \mathrm{psi}$ ) for a strain of $1 \mathrm{in}$. per inch of original length -.. even though the material in practice might fail long before such a theoretical strain value could be realized. A stiffer material, then, would have a numerically higher modulus than $2.0 \times 10^{6} \mathrm{psi}$

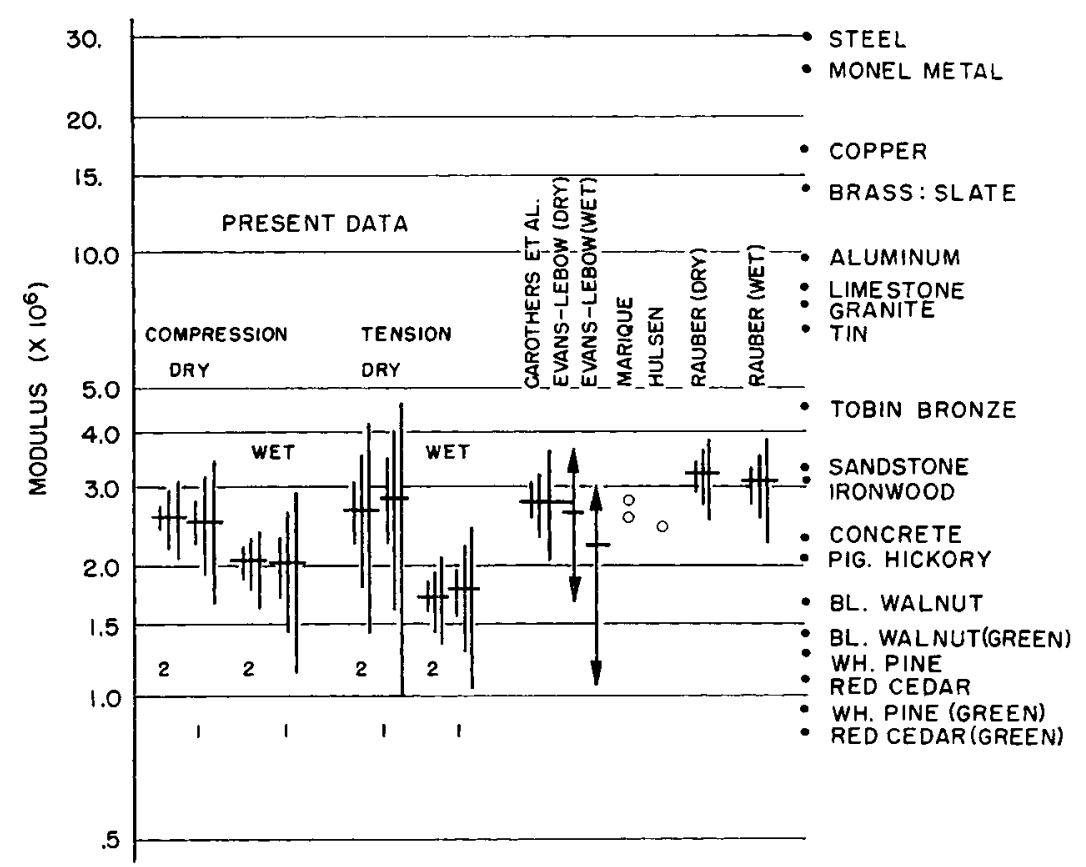

Fig. 2 The modulus of elasticity of test samples of eompact bone-dry and wet, in tension and in compression - is shown on a logarithmie plot. Arerages of present data and records from the literature are indicated by short horizontal lines; one, two and three standard deviations, respectively, are shown by the short, medium and long vertical lines that intersect. The list at the right shows the relative moduli of the substanees indicated.

and a more limber material would be lower. Elasticity modulus, expressed in terms of psi (or $\mathrm{Kg} / \mathrm{mm}^{2}$, etc.), is the accepted measure of that stiffness or limberness that would be crudely perceived as resistance if uniform splinters of various materials were bent or stretched in the fingers. Actually the conditions of test--tension, bending, compression, etc. - are specified in comparing moduli. 
Figure 2 illustrates the standard values of the modulus of elasticity for a number of common materials, ${ }^{3}$ plotted in order of magnitude along a vertical logarithmic scale. Materials of higher modulus are plotted toward the top of the figure. In comparison, our average elasticity modulus values for bone are plotted as short transverse lines. The three vertical lines that transect each transverse line represent ranges of one sigma (shortest vertical line), $2 c$, and $3 e$ (longest line). Two groups of data are summarized for each type of test; in those designated "1," strains were measured

TAIBLE 1

Average modulus of elasticity and standard deviations of bone samples tested in compression and in tension

\begin{tabular}{|c|c|c|c|c|}
\hline \multirow{2}{*}{$\frac{\text { TYPE OF ATRESS }}{\text { Compression }}$} & \multicolumn{4}{|c|}{ MODLLES OF RTASTICITY } \\
\hline & 2 Gages & No. & 1 Gage & No. \\
\hline Dry bone & $2.60 \pm .167 \times 10^{5}$ & (5) & $2.53 \pm .301 \times 10^{6}$ & (6) \\
\hline Wet bone & $2.06 \pm .117 \times 10^{6}$ & (5) & $2.04 \pm .290 \times 10^{\circ}$ & $(5)$ \\
\hline \multicolumn{5}{|l|}{ Tension } \\
\hline Dry bolle & $2.69 \pm .420 \times 10^{\mathrm{i}}$ & $(10)$ & $2.86 \pm .612 \times 10^{n}$ & $(12)$ \\
\hline Wet bone & $1.73 \pm .128 \times 10^{6}$ & $(7)$ & $1.77 \div .232 \times 10^{4}$ & (3) \\
\hline
\end{tabular}

by but one extensometer, while the better and less variable data designated " 2 " involved the use of two extensometers for the measurement of strains on each test piece. Our modulus values are shown in table 1.

It will be seen that dry skeletal bone in both tension and compression has an elasticity modulus average between 2.5 and 3.0 million psi and, thus, it has elastic properties comparable to the stiffest woods in tension, and to rolled lead, concrete, common brick or sandstone in compression. Wet adult bone in compression showed about a half million psi lower elasticity modulus than dry bone; while, in tension,

\footnotetext{
${ }^{3}$ Sources of modulus data plotted: Timoshenko and Maccullough ('46); Hodgman ('47); Wangaard ('50).
} 
wet bone averaged about a million psi lower _- in the range of the moderately hard woods (dry). ${ }^{4}$

It may be noted (fig. 2) that Marique's two values for tension modulus correspond with ours for dry bone as do the determinations on preserved cadaver bone of Carothers, Smith and Calabrisi (for compression) and of Evans and Lebow (for tension). ${ }^{5}$ Rauber's data for both dry and wet bone, however, are higher. The Fvans and Lebow ('51) averages on wet bone in tension $\left(2.27 \times 10^{6} \mathrm{psi}\right)^{6}$ though nearly a half million below values for dry bone were still higher than our equivalent data $\left(1.73 \times 10^{6} \mathrm{psi}\right)$. The relatively low modulus values of our wet-bone data, especially in tension, are undoubtedly to be attributed to the low soft tissue content and altered colloidal properties of cleaned skeletal bones. They should, however, define the lowest reasonable elastic modulus for normal living adult bone in much the way that dry bone modulus values define an upper limit.

The average elastic modulus of living bone, if available, would probably fall near or just above the wet bone level. An estimate based on the data of figure 2, assembled from both our series and those listed by other investigators, would suggest that a 2.0- to 2.5-million psi modulus (with a 30 spread above and below of about a million) would be reasonable for normal adult bone. The range indicated would assume the employment of paired extensometers. Measurements upon samples from a specific region of a given type of bone might well show less variation (Evans and Lebow, '51), but such values may be misleading as a working measure for the stiffness of compacta in a general sense since all other groups of data have shown a wide and often unempha-

\footnotetext{
${ }^{4}$ Extensive investigations have shown that the elasticity modulus of various woods decreases with increased moisture content (ef. Wangaard, '50).

sabulations of data by the various investigators when in the metric system lave been converted to the English system. The data have been treated statistically by us where possible and these data were plotted.

'The range of data of Evans and Lebow ('51) (fig. 2) may be considered as approximately a two sigma range.
} 
sized range. Living bone, if it is more like wet bone than like dry bone, should also be expected to be somewhat more limber in tension than in compression.

It should be recalled that, accompanying the lower elastic modulus for wet bone, the stress at the proportional limit was less than for dry bone. Furthermore, the stress at the proportional limit was less for wet bone in tension than for wet bone in compression. This implied that, for wet bone, permanent plastic deformation or mechanical deterioration at a molecular level began at a lower stress for tension than for compression. At a given critical stress level, then, a wet whole straight bone subjected to bending could have normal elastic bone on the concave or compressive side, while on the tensile side the bone may already have begun to deteriorate plastically.

\section{Elasticity in different axes}

Flat plates of bone having appropriate size for testing and a more or less uniform fiber direction may be machined from the tibia or from the popliteal face of the femur; and, though these may be compressed end-on (longitudinally) and sidewise (tangentially), comparable tests in a radial direction cannot be measured because the dimension is too small. Accordingly, another approach to comparing the modulus of elasticity in different axes was devised. Small cubes of bone (.15 to $.2 \mathrm{in}$. on a side) were accurately machined from the anterior part of the middle region of 4 femora and from the medial face of the mid-region of three humeri. In each instance, the upper and lower ends, the external and internal surfaces and the lateral faces of each cube were marked differentially so that the cubes could be oriented in a testing. machine (1) for longitudinal (end-to-end or parallel to fiber) compression, (2) for radial (external - medulla) compression and (3) for tangential compression.

The small size of the cubes called for a specialized device for transmitting forces. Figure 3 shows a cube of bone (B) resting upon the supporting anvil (A) of a rectangular jig' 
(J) which lay upon the testing-machine base (TMB). Compressive movements of the testing-machine head (T.IH) were transmitted to the bone by the sliding plunger (P). Paired (Tuckermann) extensometer gages (E) were fitted along an inch span covering $(P)$ the lower part of the steel plunger rod, $(B)$ the bone cube, and $(A)$ the upper part of the support rod; with this arrangement, a composite strain value

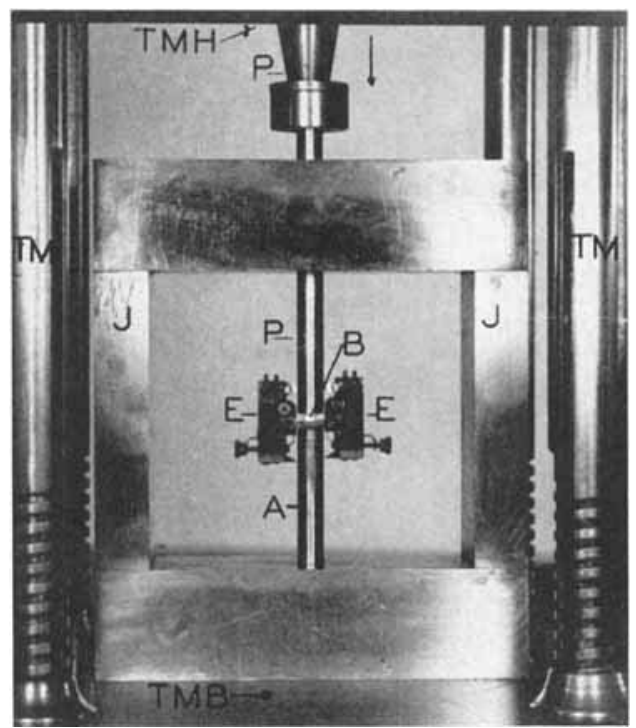

Fig. 3 The arrangement used in testing cubes of compact bone in compression. $J$ is a jig having at $A$ a fixed anvil and at $P$ a movable plunger; a cube of bone, $B$, rests between $A$ and $P$ and extensometer gages, E-E, span a length of both bone and steel. The jig rests upon the platform base, TMB, of a testing machine, TM, and pressure is transmitted through movement of the testing machine head, TMH.

was indicated by the gages, representing both a span of steel and the height of the bone cube. The strain over the span of the steel rod covered by the extensometers -- i.e., one inch minus the cube height - was deducted from the composite strain value. The residual value, i.e., strain along' the vertical dimension of the bone cube, was plotted against the appropriate stress to produce a stress-strain curve for the bone alone. From this, the modulus of elasticity was 
computed. Tests made in this way upon a number of specimen cubes from a given bone were compared according to whether the cubes were compressed longitudinally, radially or tangentially.

TABLE 2

Elastic modulus in three axes

Modulus of bony cubes compressed in each of three axes

\begin{tabular}{|c|c|c|c|c|c|}
\hline \multicolumn{2}{|c|}{ LONGITUDINAL AXIS } & \multicolumn{2}{|c|}{ RADIAL AXIS } & \multicolumn{2}{|c|}{ TANGENTIAL AXIS } \\
\hline \multicolumn{2}{|c|}{ Modulus (multiply by $10^{8}$ ) } & \multicolumn{2}{|c|}{ Modulus (multiply by $10^{6}$ ) } & \multicolumn{2}{|c|}{ Modulus (multiply by $10^{(i)}$ ) } \\
\hline \multicolumn{6}{|c|}{ Femur $(d r y)^{1}$} \\
\hline 1.67 & $(=100 \%)$ & 1.48 & $(89 \%)^{2}$ & 1.22 & $(73 \%)$ \\
\hline 1.96 & $(=100 \%)$ & 1.09 & $(56 \%)$ & 1.23 & $(63 \%)$ \\
\hline 1.54 & $(100 \%)$ & .92 & $(60 \%)$ & .96 & $(62 \%)$ \\
\hline 1.92 & $(100 \%)$ & .67 & $(35 \%)$ & .94 & $(49 \%)$ \\
\hline
\end{tabular}

Humerus $(\mathrm{dry})^{1}$

$\begin{array}{llllll}2.05 & (100 \%) & .83 & (41 \%) & .99 & (48 \%) \\ 1.86 & (100 \%) & .88 & (47 \%) & .60 & (32 \%) \\ 1.29 & (100 \%) & .55 & (43 \%) & .95 & (73 \%)\end{array}$

Average

$1.756 \pm .372=(100 \%) \quad .916 \pm .301 \quad(52 \%) \quad .912 \pm .224 \quad(52 \%)$

Wet bones - average

$1.262 \pm .231 \quad(=100 \%) \quad .546 \pm .117 \quad(43 \%) \quad .608 \pm .203 \quad(48 \%)$

Wet bones - $\%$ of dry, longitudinal average

$(35 \%)$

Wet bones - \% of dry modulus for bone similarly compressed

$(72 \%)$

$(60 \%)$

$(67 \%)$

${ }^{1}$ Each figure below represents average determinations from a given bone.

${ }^{2} \mathrm{Per}$ cent of compression along longitudinal axis.

Table 2 shows the average elasticity modulus for cubes from 7 bones in longitudinal compression and the comparable values for radial and tangential compression. In all, 63 cubes of dry bone were tested -9 from each of the 7 source bones; the cubes were assorted into three test groups of 21 cubes - three from each bone - and the cubes of each of the three test groups were tested in a given axis. In the table, the average modulus for each unit of three cubes receiving 
identical testing treatment was tabulated both according to the bone from which the cubes were cut and according to the compression direction. For all the bones that were compressed longitudinally (left column of table 2), an average elasticity modulus of $1.756 \times 10^{6}$ psi was found. In contrast, it will be noted that both the radial and tangential groups had much lower elasticity moduli; in fact, both transverse averages were the same, i.e., $52 \%$ of the longitudinal modulus. Figure 4 shows graphically the average relative stiffness of dry bone in the three axes as indicated by modulus of elasticity data. As in the earlier tests on longer columns of bone in compression, the cubes showed considerable variability, as shown both by the recorded standard deviation and by the differences in the modulus measurements for individual bones.

In addition, 21 cubes, three from each bone, were tested wet. One cube from each bone was tested in longitudinal compression, one was tested radially and the other was compressed tangentially. In longitudinal compression, the average wet bone was less stiff (lower modulus) than the average dry bone, i.e., $72 \%$ of the dry modulus (cf. fig. 4). (The comparable value for our longer test columns of wet bone in compression, shown in table 1 , was $80 \%$ of the dry modulus.) Radial and tangential tests compared to longitudinal on the wet cubes showed an even lower modulus of elasticity than did dry tests. When the averages of wet transversely-compressed groups were compared with wet cubes compressed longitudinally, they were found to be only $43 \%$ and $48 \%$ of the latter (fig. 4). When compared with dry bone compressed longitudinally, they were about a third as stiff $(31 \%$ and $35 \%$ ). Again, where the wet bone in longitudinal compression showed $72 \%$ of the dry modulus for longitudinal compression, wet bone in radial compression showed $60 \%$ of the dry radial value, while wet tangential tests showed $67 \%$ of the elasticity modulus of dry tangential tests.

The figures for average elasticity modulus on dry cubes were almost the same for both radial compression and for 
tangential compression. The variability of the individual tests, however, was considerable. Because of the similarity of the averages of radial and tangential moduli and the high standard deviation, no significant difference between radial and tangential elasticity has been demonstrated. This was true also for wet bone.

The essential feature in tests of compression along the three perpendicular axes, then, was that while no difference

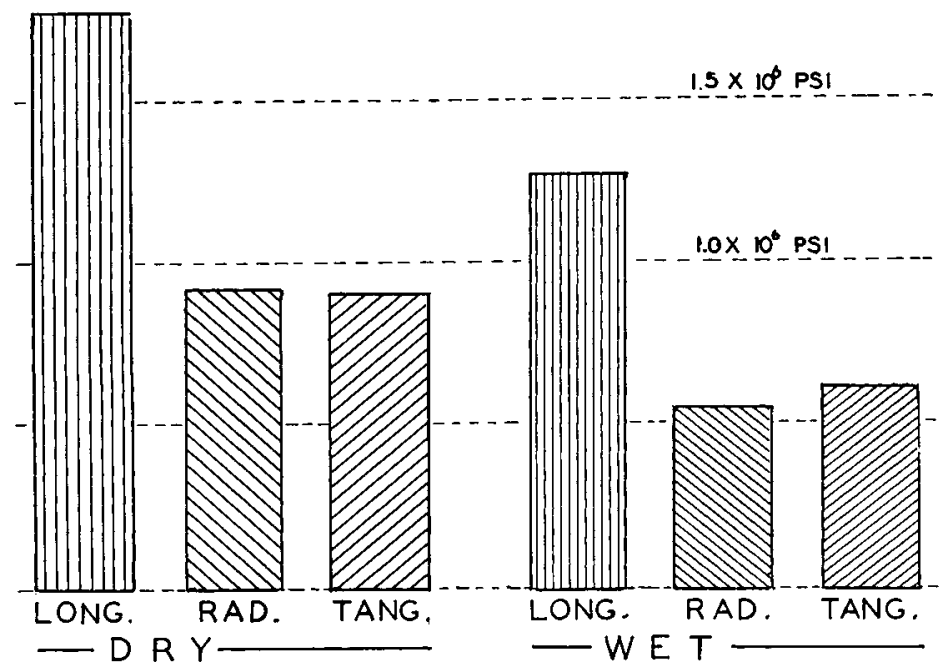

Fig. 4 Diagrammatic comparison of the average modulus of elasticity of cubes of compact bone when compressed in a longitudinal (LONG.), in a radial (RAD.) or in a tangential (TANG.) direction. Data for dry cubes of bone and for wet cubes are indicated.

showed in the elasticity modulus along axes perpendicular to the bony fibers, the modulus for this transverse compression was much less than for compression parallel to the fibers. Compression perpendicular to fibers for dry bone was almost half $(52 \%)$ the value for compression parallel to fibers; for wet bone, the modulus for transverse compression averaged $43-48 \%$ of that for compression parallel to the fibers. No equivalent data appear to be in the literature though a tacit assumption that bone is more resistant along fiber axes has 
been implied by workers using the "split-line" technique and concerned with the architecture of the trajectorial patterns of the fibrous structure of bone (Benninghoff, '25, '34; Siepel, '48).

A glance at the elasticity modulus for longitudinal compression for the cubes (table 2), on the one hand, compared with the columns of table 1, on the other, shows notably lower figures for the former measurements, i.e., cube modulus was $\pm 61 \%$ of column modulus. This numerical difference appears to be due, not to sampling differences in test specimens, but to different length to eross-section ratios. This assumption was checked by comparisons of a new set of cubes from 4 femora with short columns $(2 \times$ cube height) and long columns from the same bones. The short columns in every instance ( 8 values) showed a modulus that was intermediate between the cube and long-column moduli. The difference in value between our cube and long-column modulus, however, is irrelevant to the central observations here dealing with a comparison, under strictly comparable conditions, of relative moduli due to the compression applied to the opposed faces of cubes in three mutually perpendicular axes.

Tension moduli in different axes cannot be tested in a comparable fashion on small samples. Suggestive data, however, on dry spindles from 7 tibiae were obtained from torsion tests. These showed a torsional (shear) modulus of 807,000 $\pm 72,000$ (1 0 ) psi. In these torsion tests one end of a cylindrical spindle specimen was held firmly and the other end was turned or twisted. If a small square were to be marked on the cylindrical surface with two sides parallel to the axis, it can be shown that one diagonal would have stretched and the other diagonal would have compressed. This torsional modulus is proportional to the tensile modulus of the material along the diagonals discussed. The tensile modulus thus figured is 2.5 times 807,000 psi or about 2,020,000 psi. This modulus value for dry bone in this oblique direction is to be compared with the average values (table 1) of 2,600,000 in comppression and 2,690,000 psi in tension where the force 
was applied parallel to the fibers. The relatively low torsion modulus found in comparison with those for longitudinal tension or compression reflects a lower stiffness in axes other than (oblique to) the longitudinal.

\section{Tensile and compressive strength}

The ultimate tensile strength is the final stress borne by a test specimen at the moment it fails and breaks under a tension load. Similarly, the ultimate compressive strength is the compressive stress at failure. Table 3 summarizes our data for the tensile and compressive strengths of bone, and

TAB LAF

Ultimate compressive and tensile strength

\begin{tabular}{|c|c|c|}
\hline IN COMPRESSION & VLTTMATE STRESS $\sigma$ & No. \\
\hline Dry bone & $25,680 \pm 4740 \mathrm{psi}$ & $(38)$ \\
\hline Wet bone & $15,775 \pm 3880$ psi & $(29)$ \\
\hline \multicolumn{3}{|l|}{ IN TEXSION } \\
\hline Dryr bone & $17,090 \pm 3940 \mathrm{psi}$ & (11) \\
\hline Wet bone & $11,428 \pm 1540 \quad \mathrm{psi}$ & (14) \\
\hline
\end{tabular}

figure 5 shows the relation of these data to those of previous investigators ${ }^{7}$ and to the standard values for common structural materials.

The compressive strength of dry bone (according to our data and to those also of Rauber, of Carothers, Smith and Calabrisi, and of Calabrisi and Smith) average close to 25,000 psi and the $3-0$ range is roughly $\pm 10,000$ psi. The individual Hülsen and Marique figures are consistent with the above average. For wet bone, however, the compressive strength is less. In Rauber's 4 specimens, it averaged less also. Calabrisi and Smith indicated that embalmed bone was ordinarily slightly weaker than the fresh bone.

The recent work on tensile strength by Evans and Lebow ('5I) is shown in histograms and thus it does not lend itself to inclusion in this summary. 
For both wet and dry bone, the compressive strength fell in the range of averages for the stronger types of building stone; it was definitely weaker than the common construction metals but was stronger than brick, concrete and the strongest of woods. Dry bone averaged stronger than granite but, like wood, bone was stronger dry than when wet (green).

Dry bone (except in the data of Carothers, Smith and Calabrisi which showed higher values than other studies)

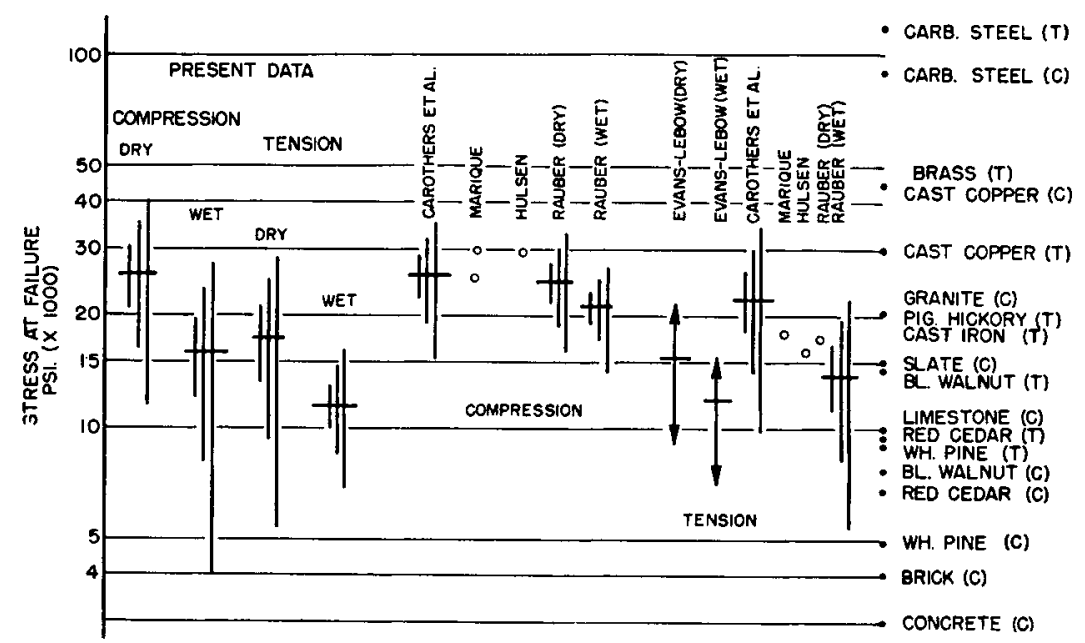

Fig. 5 Stresses at failure of compact bone, from present data and from the literature, are shown on a logarithmic scale. Dry and wet bone and the conditions of tension or compression are included. The lengths of the vertical lines indicate ranges of one, two, and thiee standard deviations and the short intersecting horizontal lines represent arerages. At the right are indicated the strengths at failure of some representative materials.

averaged in tension just over 15,000 psi - a figure about 10,000 psi less than the equivalent compression value. It was thus in the strength range of the strongest woods (dry) and the weaker structural metals. The $3-c$ range for dry bone in tension was 10,000 psi. The tension data of figure 5 indicate also that wet bone was 3,000 to 5,000 psi less strong than dry bone.

When our average tensile and compressive strengths were compared, bone appeared to be less strong in tension than 
in compression, and this difference showed when either wet or dry tests were compared. The average relative strengths are shown graphically in figure 6 . In tension, wet bone was roughly 5,000 psi weaker than in compression, while dry bone was weaker in tension by 8,000 psi (or 4,000 psi in data of Carothers, Smith and Calabrisi). This difference in tensile and compressive strengths contrasted markedly with wood, where tensile strength is notably greater than compressive strength.

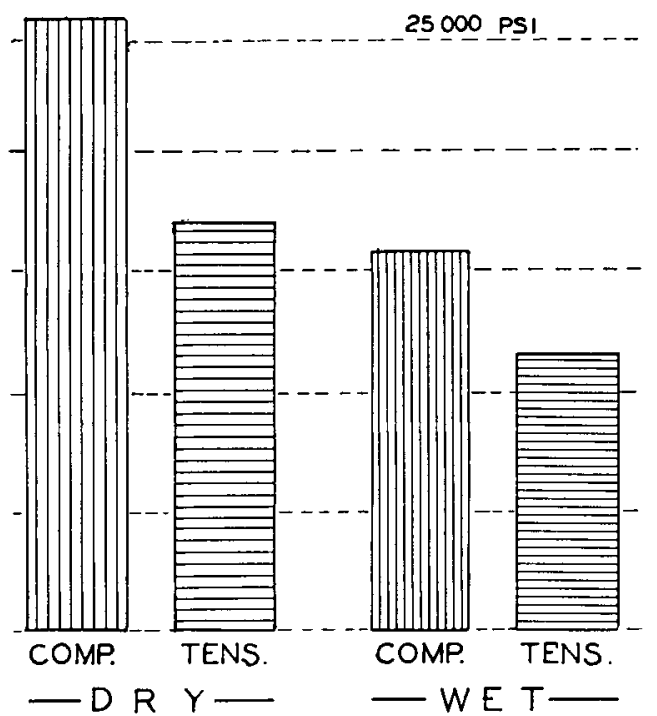

Fig. 6 Diagrams showing the relative strength at failure of test pieces of compact bone - wet or dry - when compressed or tensed to the breaking point.

The distinction in tensile and compressive strength values (fig. 6) points to a notable feature regarding bone. The ultimate tensile and compressive strengths refer, it should be recalled, to stress loads at failure - i.e., fracture. Where tensile strength is less than compressive strength as in bone, a rod of bone, subjected to pure bending till fracture, fails first on the tension side of the member, and the fracture progresses through to the opposite side of the cross section. Though the architecture of an intact living tubular bone may be specialized to resist bending through increased cortex 
diameter, through thickening or increase of mass on the tension side or through regional increase in strength, these differences merely diminish stress values to which the bone is subjected. The bone, nevertheless, if it fails in pure bending, does so by a fracture beginning on the tension surface as long as the tensile strength of the material is less than its compressive strength.

Data from Evans and Lebow ('51, '52) show that the average tensile strength of the lateral quadrant of the shaft of the femur (the tensile side for normal weight bearing) is relatively greater than that for the other quadrants. The difference in tensile strength of the lateral quadrant, however, was but a few hundred psi above the weaker quadrants. Although equivalent compressive values were not indicated, the low range of tensile differences suggested no contradictory evidence affecting the general relation between tensile and compressive strength at failure. The differences noted by Evans and Lebow must point to a functional mechanism through which bone increases its density and reduces its bulk locally without reducing its tensile strength. Studies on failure of whole bones in bending (Messerer, 1880; Carothers, Smith and Calabrisi, '49; and Evans, Pedersen and Lissner, '51) indicate that failure is in part explained by the relative tensile weakness of bone.

Hvans and Lebow ('51) have shown consistent and still lower ultimate shearing strength data (av. wet: 9,800 psi; dry: $8,000 \mathrm{psi}$ ) for tests on bone perpendicular to the long axis. Rauber's single determination, howerer, was higher' - in his tension range - but for shear parallel to fibers his value was 7,200 psi. Though data on bone for shear parallel to fiber are grossly inadequate, the suggested relative shear weakness of bone recalls the much greater relative weakness in wood (ef. Wangaard).

Dry spindles from 6 tibiae when subjected to torsion about the longitudinal axis showed a torsional shear strength of $10,633 \pm 1140(1 \circ)$ psi. This shear value, like those quoted 
above, was below all of the average tensile strength figures for bone though the two ranges overlapped somewhat.

\section{Compressive strength in different axes}

The cubes of bone that were subjected to determinations of the elasticity modulus (table 2 and fig. 4) were compressed

TABLE 4

Compressive strength in various axes

Comparison of cubes of compact bone compressed in each of three axes

\begin{tabular}{|c|c|c|c|c|}
\hline \multirow{2}{*}{$\frac{\text { LONGITUDINAL AXIS }}{\text { Stress }(p s i)}$} & \multicolumn{2}{|c|}{ RADIAL AXIS } & \multicolumn{2}{|c|}{ TANGENTIAL AXIS } \\
\hline & Stress (psi) & $\begin{array}{l}\% \text { longit. } \\
\text { stress }\end{array}$ & Stress (psi) & $\begin{array}{l}\% \text { longit. } \\
\text { stresss }\end{array}$ \\
\hline \multicolumn{5}{|l|}{ Femur (dry) } \\
\hline 33,450 & 27,907 & $(83 \%)$ & 24,333 & $(72 \%)$ \\
\hline 31,525 & 21,553 & $(69 \%)$ & 22,100 & $(70 \%)$ \\
\hline 27,317 & 17,483 & $(64 \%)$ & 15,200 & $(56 \%)$ \\
\hline 30,050 & 19,367 & $(63 \%)$ & 19,433 & $(64 \%)$ \\
\hline \multicolumn{5}{|l|}{ Humerus (dry) } \\
\hline 26,583 & 17,167 & $(64 \%)$ & 12,183 & $(45 \%)$ \\
\hline 31,200 & 21,633 & $(67 \%)$ & 18,900 & $(61 \%)$ \\
\hline 26,900 & 11,950 & $(44 \%)$ & 18,567 & $(69 \%)$ \\
\hline \multicolumn{5}{|c|}{ Average (dry bones - 21 specimens in each group) } \\
\hline $29,575 \pm 2580$ & $19,203 \pm$ & $9(65 \pm 10.7 \%)$ & $18,653 \pm$ & $4(63 \pm 10.4 \%)$ \\
\hline
\end{tabular}

Average (wet bones -7 specimens in eacl group)

$19,007 \pm 3100(=100 \%) \quad 16,988 \pm 4600(=89 \%) \quad 15,336 \pm 2800(=82 \%)$

\% of dry bone similarly compressed

$64 \%$ of dry long. $\quad 88 \%$ of dry rad. $\quad 80 \%$ of dry tang.

$\%$ of dry long. strength

$64 \% \quad 57 \% \quad 52 \%$

to failure. The stresses at rupture (compressive strength) are summarized in table 4 and figure 7 . The compressive strength for the dry cubes from 7 bones where the force was applied parallel to the fibers (i.e., longitudinally), varied from 25,000 to $33,850 \mathrm{psi}$; thus, it corresponded with the aver.age to stronger dry columns of table 3 . In this respect, bone did not show a difference in response such as that which 
appeared in the comparison of modulus data derived from cubes or from columns; strength tests by Calabrisi and Smith also showed that very small test pieces gave data comparable to those derived from large specimens.

The data of table 4 and figure 7 show that the average strength of dry bone in radial compression is $65 \%$ of the

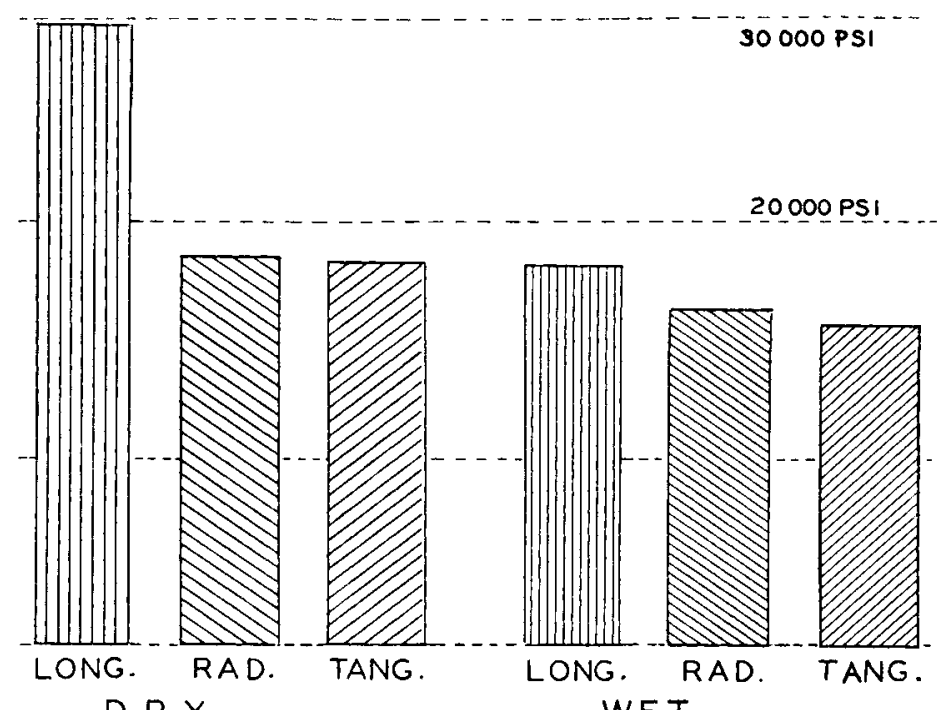

Fig. $\tau$ Bar diagrams of the relative strength at failure of cubes of compact bone - wet and dry - when eompressed longitudinally (LONG.), radially (RAD.) and tangentially ('TANG.).

strength for longitudinal compression. Tangential compressive strength was $63 \%$ of longitudinal strength. These averages suggest that radial and tangential strength are nearly the same - about two-thirds of longitudinal compressive strength; a standard deviation, however, of over $10 \%$ indicates a considerable variability about the average figures. Characteristically, however, a consistently lower strength was shown in transverse compression compared to longitudinal. The stress values at failure for transverse compression were in the range of values for dry columns in tension or wet columns in compression (cf. table 3). This was also 
shown in Rauber's three tests where, however, compression at a right angle to fibers ranged from $91 \%$ to $72 \%$ of the equivalent longitudinal values.

The compressive strength tests showed wet bone to be significantly stronger in longitudinal compression than in transverse compression. In radial compression, wet bone had $89 \%$ of longitudinal wet bone strength; in tangential compression, the equivalent value was $82 \%$ of wet bone strength in longitudinal compression. Wet bone in longitudinal compression compared to similarly compressed dry bone showed about two-thirds (64\%) the strength of dry bone; wet bone in radial compression showed, however, $88 \%$ of the dry bone strength in radial compression; and wet bone in tangential compression showed $80 \%$ dry bone tangential compression. When average radial compressive strength wet was compared with longitudinal strength dry, it showed $57 \%$ of the latter figure. Tangential strength was $52 \%$ of the dry longitudinal compressive strength. Again, in view of the variability of the data, no assumption of a significant difference between radial and tangential strengths is warranted.

The compacta of long bone was characterized by three mutually perpendicular coordinate axes which differed in strength. In view of the predominant longitudinal strength, which correspond with the principal direction of Haversian systems, bone is clearly non-isotropic, or orthotropic. Bone in this respect is like wood. It should be noted, though, that in wood differential shrinkage due to the drying of lumber may cause checks in the radial direction or shakes tangentially along the growth rings, and these split-defects may weaken one axis more than the other to perpendicular loads. In clear test specimens of wood, however, either dry or green, if there are no such longitudinal cleavages, one side axis does not greatly differ from the other in transverse crushing strength (Wangaard). Bone, again, in this respect also appears to be like wood. 
It was of interest to examine the faces of the cubes after compressive failure for evidence of fracture. Sometimes, in specimens not showing clearly, a drop of oil placed on at cube face cleared the bone so that air trapped in a fracture crevice showed as a white contrasting line. On examination, the 84 specimens, after testing, could be separated on the basis of fracture pattern into two groups that corresponded to the direction of compression: (1) a group subjected to longitudinal pressure and (2) the remainder which failed in either radial or tangential compression. In both groups, the failure due to compression was a shearing failure in which one part of the cube slipped en masse relative to another part along one or more oblique slip planes. As shown in figure $8 \mathrm{~A}$, the first group, although somewhat variable in detail, showed an oblique cleavage; one extremity of the fracture slip plane ran along or adjacent to one of the edges at a compression face, and the oblique shear plane extended through the bone at a steep angle, roughly $30^{\circ}$ to the perpendicular, to the middle of the compression face opposite (fig. 8A). At times, the fracture plane was biased so that a corner piece rather than a whole side was sheared from the main piece. The fracture line was often jagged, irregular or doubly cleaved.

In contrast, under radial or tangential compression, two shear planes, both relatively smooth-faced, began at or near opposite edges of compression faces - always at edges parallel to fibers - and these fracture planes extended through the cube as single or double $45^{\circ}$ shear planes (fig. 8B). On the end sections, the two shear planes showed an "X" crossing of the fracture planes near the middle of the face. No difference could be observed between radial and tangential compression failures. It should be noted that the conditions of force application (figs. 8A, 8B) differ significantly only insofar as the orientation of the cubes affected the tests. The latter X-type shear failure involved much lower stress values.

Figure $8 \mathrm{C}$ in contrast shows a representative failure in a longer, rectangular section, column of bone $(.16 \times .25 \times .8 \mathrm{in}$. $)$ 
subjected to longitudinal compression. Testing machine pressure was continued longer than enough to cause initial failure so that the injury was exaggerated. Where the cube at $8 \mathrm{~A}$ had a fracture running from end to end which was obviously

A

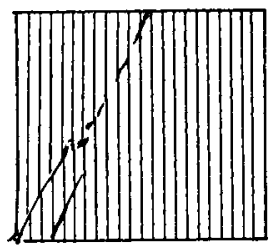

B

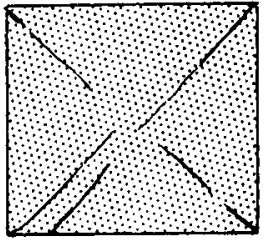

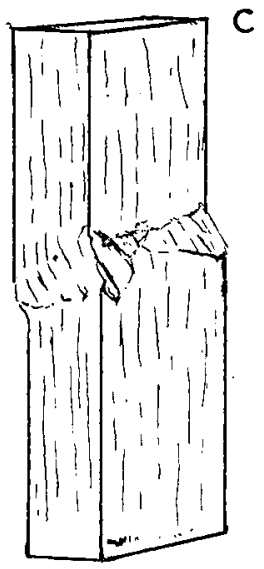
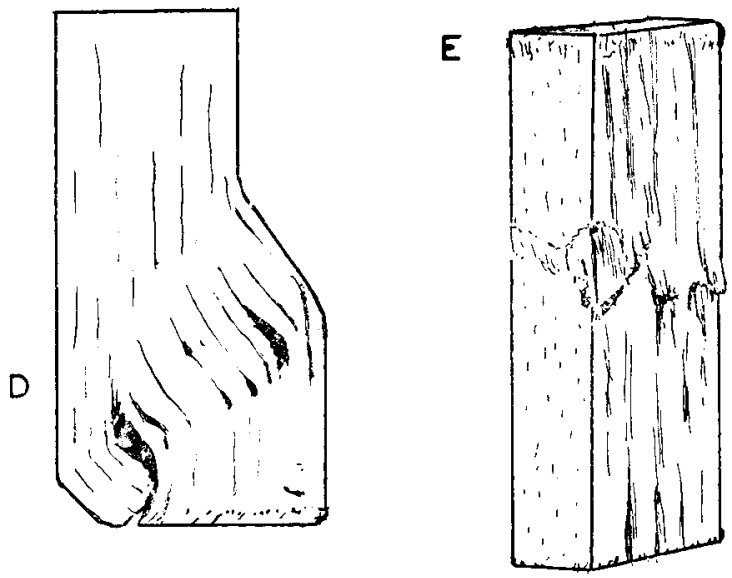

Fig. 8 A, The type of fracture shown when cubes of compact bone have been compressed longitudinally till failure.

$B$, The type of fracture at failure when eubes of bone were compressed radially or tangentially.

C, A representative fracture in a column of bone subjected to compression.

1) Failure in a column of bone showing longitudinal cleavages and crushing effects.

$\mathbf{E}$, Fracture in a column of hard wood showing similarities to the failure at $\mathrm{C}$.

affected by the plunger-anvil contact, the fracture of the column sought a region of inherent weakness between regions of stronger bone. The transverse rupture lines were somewhat oblique, however. There was also evidence of splitting or tearing apart in the transverse axes due to lateral expan- 
sion accompanying the longitudinal compression. The material tended to split along the length of the Haversian columns leading to chip fragmentation. Finer correlations with the microscopic anatomy were not made.

Figure $8 \mathrm{D}$ shows more prominent lengthwise cleavages and a secondary crushing effect superimposed on the shear injury and the loss of lateral cohesion. A comparable fracture of a small rectangular prism of hard wood at $8 \mathrm{E}$, like bone, showed a generally oblique cleavage, chipping and splintering. Minor differences in pattern, splintering, etc., obviously reflect both differences in structural organization and intimate mechanical properties.

\section{CONCLUSIONS}

Since bone consists of both a formed protein matrix and a coextensive calcareous constituent, our specimens from cleaned and dried skeletal material are definitely altered relative to living bone. Our dry test specimens with both desiccated matrix and inorganic components existing as solids - but with an essentially unchanged Haversian bony morphology - provide a test material that is probably stiffer mechanically, elastic over a longer range and stronger than living bone. Such dry bone and other dry bone, whether preserved or merely mummified, should define maximum values not likely to be exceeded by normal living bone. Conversely, soaking of such bone in water should provide an artificial degree of hydration - like soaked gelatin - without the nice physiological balance in colloidal properties found in life. To a degree, such test material should be closer to the properties of living bone, but the deterioration of the formed softtissue elements of the Haversian canals and excess hydration should bring forth lower values for the mechanical constants. The span, therefore, between dry and wet determinations should be of special biological interest.

Up to its proportional limit, bone returns to its original dimensions when it is unloaded. Beyond the proportional limit, it still has the ability to bear increasing loads, though 
it is subject to permanent deformations of a plastic sort. Our tests and those of others have shown a wide range of variability in both stiffness and strength. Such variation reflects differences from one region to another in a given bone, differences for the same region from individual to individual, and possibly differences from one bone to another in an individual. Withal, the test values parallel to fiber, especially in compression, are greater than for the common structural hard woods. Bone with such properties in its elastic range, approximates more or less the rigid solid body required for protection, support of weight and mechanical functioning. Under a common range of imposed forces, it is normally an efficient and competent material.

Properties like strength, resilience and toughness come into the picture when bone is exposed to an exceptional range of stresses. The tests here show bone to be a unique material, since both wet and dry bone show less strength in tension than in compression. In wet bone, furthermore, both the elasticity modulus and the proportional limit are less in tension also. This implies that when a bone bends on loading and acquires a deformation with a convex and a concave side, further bending will cause the convex surface to enter a range beyond its proportional limit. Such bone on the convex tension surface of a member becomes plastic and deteriorates with further loading while the compressed bone on the concave side is still fully competent and is in its elastic range. When bending stresses are excessive, fracture will begin on the tension surface and travel through the bone to the compression side.

Since the work of Roux (1885, 1893) and Wolff (1892) it has been almost axiomatic that living bone responds to persistent forces and that it transforms and adapts its structure to altered conditions of loading. If bone deformations never exceed transient elastic changes due to loads borne within the elastic limit, structural changes in bone are clearly not responses to wear and tear. The stimulus to transformation must be due to some interface reaction or differential shear- 
ing between an osseous surface and the adjacent soft tissues (Altmann, '50). If osteogenic processes are directly responsive to physical stimuli, one may expect then that new bone would be added to about the same degree on both compressed and tensed surfaces. On the other hand, if a bone subjected to bending has one side in tension beyond the proportional limit, while the compressed side responds aceording to Hooke's law, the tensed side should provide a greater physical stimulus than the compressed side.

In either instance, whether tensile or compressive stimuli are similar or whether tensile stimuli are greater, the situation should be visualized at a microscopic level. As scen histologically, the most recent lamellae at bony surfaces form an osteoid coating that serves as a substrate to osteoblasts and as a site for matrix calcification. It must have mechanical properties different from (probably more limber than) those found in the deeper, fully calcified bone. Interposed between soft tissues and older bone, uncalcified osteoid must diffuse stresses according to its properties, and it may be a factor of significance in determining the extensiveness of regional osteogenic responses to strains or forces.

One might expect, by analogy with other materials, that loading of long duration or intermittent loading near the proportional limit might cause living bones to yield and show a plastic deformation called "creep." This, in the light of the differential between the compressive and tensile properties of bone, should provide the greatest physical stimulus to reconstruction in regions subjected to tensile deformation. Furthermore, if plastic deformation at a molecular level affects one region of a bone and not another, such deterioration may secondarily induce a mobilization of material which may, in turn, become an effective stimulus for reparative processes. In any case, it is of interest to know how reconstructive processes (activities of osteoblasts) are directed to one specific locus on a bony surface rather than to another. The present study affirms that regions affected by tensile 
stress, or shear, beyond the proportional limit should first evoke reconstructive changes.

No significant difference could be demonstrated for radially compressed bone when compared with tangentially compressed bone in either modulus or strength - wet or dry. Such compressed bone had much less strength in lateral conpression than parallel to fiber and it failed in simple shear.

Compared to the knowledge of wood or engineering struetural materials, information on bone is fragmentary. 'This applies especially to information on toughness, i.e., the energyabsorbing properties on impact (the Evans and Lebow data have approached this through percentage elongation but there are other methods as yet untried), on brittleness, on shear and torsional modulus and on shear strength parallel to fibers. The oblique, rolling, sliding type of failure in cubes of bone in lateral compression suggests an especial weakness in shear parallel to fibers. This is indicated also by compression tests on hollow cylinders of bone compressed longitudinally by Carothers, Smith and Calabrisi, which showed longitudinal splitting and shear, and by the accompanying figures $8 \mathrm{C}$ and $8 \mathrm{D}$ above. The common spiral fracture in long bones due to torsion and fractures due to pure bending of a bone should, in contrast, be viewed in terms of tension weakness.

Bone, in the sense of this paper, is the grossly solid osseous structural material of which the skeleton is constructed. Bones, in a larger sense, have both a gross and a microscopic architecture that is determined in large part by genetic factors, by growth, and by the common range of stresses borne. Long bones, for instance, have a tubular structure; the cortex is thick in some regions and thin in others; the cross-section profile may be small or large and it may be round or triangular; the axis connecting the centroids of suceessive sections may be curved or spiralled; and the trabecular bone may be heavy in regions or light. The characteristic shape of long bones (Koch, '17; Thompson, '42) appears to be in harmony with a principle of maximum possible strength 
through an economical use of material. The patterns of osteone architecture for the flat bones are interpreted in this way also (Benninghoff, '25).

Bones, however, do fail under excessive loading and impact. To explain why a given bone may fail according to a certain pattern it is necessary to know: (1) the characteristic weaknesses of the material, i.e., the relative weakness in shear, in longitudinal tension and in lateral tension also, (2) the mechanical form of the bone, and (3) the point of application and type of a damaging force and its magnitude and direction. The mechanical form of a bone is a complex of factors including the curvatures and shape of the bone, the sectional distribution of the resistant material, the character of the internal pressure-equalizing system due to the enclosed semifluid content of the medulla, the character of adjoining bones as force transmitters, and the shock-absorbing specializations. These latter include trabecular bone, the enclosed marrow, the coating of periosteum and articular cartilage and the overlying soft tissue padding.

The study of bone failure and the correlation with the properties of bony material are still incomplete in accounting for why bones break as they do under excessive impacts and loading, despite some attention by various investigators (Messerer, 1880; Kuntscher, '35; Gurdjian and Lissner, '45, '46; Evans and Lissner, '48; Evans, Lissner and Pedersen, '†8; Carothers, Smith and Calabrisi, '49; Gurdjian, Webster and Lissner, '49; Pedersen, Evans and Lissner, '49; and Evans, Pedersen and Lissner, '51).

\section{SUMMARY}

Test pieces of compact bone were machined from the larger long bones (dry human skeletal material) and were tested in compression and in tension in engineering testing machines. The stiffness or modulus of elasticity and the tensile and compressive strengths were determined for both dry and water-soaked specimens. 
Dry bone has less strength in tension than in compression, but the modulus values are similar. Wet bone, presumably like living bone, is less stiff than dry bone - especially in tension - and its strength is less, again especially in tension.

In addition, cubes of bone were compressed longitudinally (parallel to fiber), radially (surface to marrow) and tangentially. No significant difference could be detected between radial and tangential compression for either modulus of elasticity or strength - dry or wet. Both transverse axes, however, are less stiff and are much weaker than the longitudinal axis is for both measures - again both wet and dry. Bone thus is shown to be a non-isotropic or orthotropic material like wood. The findings are discussed in relation to data in the literature and to their significance in determining the effective and the weak features of bone.

\section{LITERATURE CITED}

ALTMANN, K. 1950 Experimentelle Untersuchungen über mechanische Ursachen der Knochenbildung. Ztschr. Anat. Entw.-gesch., 114: 457-476.

Benninghoff, A. 1925 Spalteinien am Knochen, eine Methode zur Ermittelung der Arelitektur platter Knochen. Verhandl. Anat. Gesellesch., 34: 189-206.

1934 Die Architektur der Kiefer und ihrer Weichteilbedeckungen. Paradentium, 6: 2-20.

Calabrisi, P., AND F. C. SMith 1951 The effects of embalming on the compressive strength of a few specimens of compact human bone. Naval Med. Res. Inst. Project NH/R-NM001 056.02 MR-51-2 : 1-3.

Carotilers, C. O., F. C. SMith and P. Calabrisi 1949 The elastieity and strength of some long bones of the human body. Naval Med. Res. Inst. Project NM 001056.02 .13 : 1-18.

Evans, F. G., ANd M. Jebow 1951 Regional differences in some of the physieal properties of the human femur. J. Appl. Physiol., 3: 563-572.

1952 The strength of human compact bone as revealed by engineering techniques. Am. J. Surg., 83: 326-331.

Evans, F. G., AND H. R. LISSNER 1948 "Stresscoat" deformation studies of the femur under static vertical loading. Anat. Rec., 100: 159-190.

Evans, F. G., H. R. Lissn Fr AND H. E. PEDERSEN 1948 Deformation studies of the femur under dynamic vertical loading. Anat. Rec., 101: 225-241.

Evans, F. G., H. E. Pedersen and H. R. Lissner. 1951 The role of tensile stress in the mechanism of femoral fractures. J. Bone Joint Surg., $33-A: 485-501$. 
GURdJIAN, E. S., AND H. R. LISSNER 1945 Deformation of the skull in head injury. A study with the "stresscoat", technique. Surg. Gyn. Obs., 81: $679-687$.

1946 Deformations of the skull in head injury studied by the

"stresseoat" technique, quantitative determinations. Surg. Grn. Obs., 83: $219-233$.

Gtrdjtan, E. S., J. E. Webster AND H. R. Lissnfr 1949 Studies on skull fracture with partichlar reference to engineering factors. Am. J. Surg., $78: 736-\pi 42$.

Faluerman 1935 Die Bezichungen des Werkstoffmechanik und Werkstofforschung zur allgemeinen Knochenmedhanik. Verhandl. Deutsch. Orthopid. Gesellsch., 29 Kongr. (1934): $347-360$.

Hodgman, C. D., Eu. 1947 Handbook of Chemistry and Plysies. 30th ext., 2686 pp. Chemical Rubber Pub. Co., Cleveland.

HüLSEN, C. 1898 Sperifisehes Gewicht, Elastizitit und Festigkeit des Knochengewebes. 13ull. Lab. Biol. St. Petersburg, 1: 7-37. Abstr. J. Sehaffer, 1898, Jahresher. übre die Fortsel. Anat. Huntwickgesch., 4 (Neue Folge): 146.

Kocr, J. C. 1917 The laws of bone arehitecture. Am. T. Anat., 21: 177-298.

KüNTscher, G. 1935 Die Bedentung der Darstellung des Kraftflusses im Knochen für dic Chirurgie. Areh. klin. Chir., 18: 489-551.

MArique, P. 1945 Études sur le Fémur; Anatomie: Axes et Angles; Deformations; Résistance. 180 pp. Stoops, Bruxelles.

MessERER, O. 1880 Über Elasticitiit und Festigkeit der menschlichen Knochen. 103 pp. Cotta, Stuttgart.

Murray, P. D. F. 1936 Bones, a Study of the Development and Structure of the Vertebrate Skeleton. 203 pp. Cambridge Tniv. Press, London.

Pedersen, 1f. E., F. G. Evans and II. R. Lissner 1949 Deformation sturlies of the femur under various loadings and orientations. Anat. Rec, 10\%: $159-1.85$.

RaUber, A. A. 1876 Flasticitä und Festigkeit der Kuochen. Anatomischphysiologische Studie. 75 pp. lingelmamn, Leipzig.

Roux, W. 1885 Beitrige zur Morphologie der functionellen Aupassung. 3. Besthrebung und Erläuterung einer knödlernen Kniegelenksanchylose. Arch. Anat. Physiol., Anat. Abt.: 120-158.

1893 Das Gesetz der Transformation der Knochen. I. Theoretischer Theil. Berl. klin. Wochenselur., 30: 509-511, 533-535, 557-558.

SeIPte, C. M. 1948 Trajectories of the jaws. Acta Odontol. Scand., 8: 81-191.

Thompson, D. W. 1942 On Crowth and Form. 1116 pp. Macmillan, N. Y.

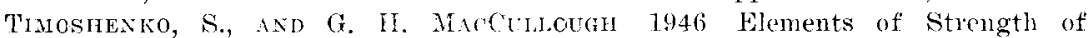
Materials. 2nd ed., $371 \mathrm{pp}$. Van Nostrand, New York.

Wangando, E. F. 1950 The Merhanical Properties of Wood. 377 pp. Wiley, New York.

WEINMAN, J. P., AND H. SICIIER 1947 Bone and Bones, fundamentals of bone biology. 464 pp. Mosby, St. Louis.

Whrtheim, G. 1847 Mémoire sur l'élasticité et la colésion des principaux tissus du corps humain. Amm. de Chim. et de Phys., 21 ( $3^{\circ}$ ser.) : 385-414.

WolfF, J. 1892 Das Gesetz dex Transformation der Knochen. 152 pp. Hirschwald, Bertin. 